\title{
Structural System Selection Using the Integration of Multi-Attribute-Decision-Making (MADM) Methods
}

\author{
Gul Polat ${ }^{1 *}$, Harun Turkoglu¹, Atilla Damci ${ }^{1}$ \\ 1 Department of Civil Engineering, Faculty of Civil Engineering, Istanbul Technical University, Istanbul Teknik Universitesi, \\ Insaat Fakultesi, Maslak, 34469, Istanbul, Turkey \\ * Corresponding author, e-mail: polatgu@itu.edu.tr
}

Received: 12 June 2018, Accepted: 25 June 2018, Published online: 29 June 2018

\begin{abstract}
A structural system carries all loads acting on the building and transfers them effectively to the soil through the foundation. Since it is the essential component of a building, selecting the most appropriate structural system is one of the critical decisions in the structural design. The design team, which consists of engineers and architects, is responsible for determining the structural system that will satisfy the owner's and end user's needs as well as the legal requirements. Due to the fact that a number of compromising and conflicting criteria may affect the structural system selection process, it is a difficult task and it should be considered as a multi-attribute-decisionmaking (MADM) problem. The main objective of this study is to provide the design teams with a MADM approach that will assist them in selecting the most appropriate structural system in a more objective and systematic manner. In the proposed approach, analytic hierarchy process (AHP) is used to compute the weights of the criteria and Vise Kriterijumska Optimizacija I Kompromisno Resenje (VIKOR) is employed to rank the structural system alternatives. In order to demonstrate how the proposed can be applied in a real life problem, the structural system of a housing project in Istanbul, Turkey is selected via this approach. The findings of the model were discussed with the decision making team in the studied project and they stated that the proposed approach could be easily employed as a guideline in selecting the most appropriate structural system from the managerial viewpoint. This paper is the revised version of the paper that has been published in the proceedings of the Creative Construction Conference 2018 (Polat et al., 2018).
\end{abstract}

Keywords

AHP, VIKOR, multi-attribute-decision making, structural system selection, case study

\section{Introduction}

Selection of a structural system is the preliminary task in the entire structural design process, whose result proposes general arrangement of the structure, incorporates the overall form, geometry, and suggests structural elements (Balali et al., 2014b). A structural system must be able to perform the task of carrying all loads and transferring them safely to the soil through the foundation (Shamrani and Schierle, 2007). Since the structural system determines the cost, duration, performance, safety, and aesthetics of a constructed facility, selection of the most appropriate structural system is crucial (Chen and Lui, 2005).

The recent advancements in structural system alternatives have brought about a competitive environment, which made the selection of the most appropriate structural system for a specific project a difficult task (Balali et al., 2014b). In building projects, different material alternatives can be preferred in structural systems such as reinforced concrete, steel, precast, masonry, wood, composite, etc. Each material has its own superiorities and inferiorities. For example, while wood buildings are light and relatively cheap, reinforced concrete buildings can resist wind loads, and steel structures allow large spans and resist seismic loads (Golabchi, 2008).

An appropriate structural system is rarely selected by a single decision maker. In general, the design team, which involves engineers and architects, is in charge of determining the structural system that will satisfy the owner's and end user's needs as well as the legal requirements. During the structural system selection process, the design team should take into account the trade-off among different alternatives, maximize the agreement between all interested parties, and thereby reach a consensus (Balali et al., 2014c).

Various factors may affect the selection of a structural system from the managerial viewpoint. Although there is no consensus on the evaluation criteria, economic life cycle, 
environmental issues, safety issues, and durability should be addressed by decision makers (Balali et al., 2010). In addition to these criteria, project characteristics and constructability issues should be considered during the selection process (Tabarak and Sher, 2003; Rivard and Leclercq, 2006).

Since the structural system selection process is affected by several compromising and conflicting criteria, it can be considered as a MADM problem. Moreover, this problem should be handled by a group of decision makers and the employed approach should allow group decision making.

In the literature, there are several studies that focus on structural system selection problem from the managerial viewpoint. Messner et al. (1994) employed artificial neural network (ANN) for the selection of structural systems. Rogers (2000) employed the elimination and choice expressing the reality III (ELECTRE III) method for selecting the housing construction processes. Tabarak and Sher (2003) ANN for selection of the buildable structural systems. Rivard and Leclercq (2006) dealt with architectural sketches for selecting feasible structural systems. Shamrani and Schierle (2007) proposed a procedure for selecting optimum structural systems and materials. Golabchi (2008) developed a knowledge-based expert system named structural selection expert system (SSE) for selecting structural systems for large spans. Wong et al. (2008) used AHP and ANP for assessing the intelligence of intelligent building systems. Balali et al. (2010) investigated the applicability of preference ranking organization method for enrich evaluation (PROMETHEE) method in structural system selection. Balali et al. (2014a) developed a multi-criteria decision-making model for selecting appropriate material, construction technique, and structural system of bridges. Balali et al. (2014b) proposed an integrated approach, which uses ELECTRE III and PROMETHEE II methods, for selecting appropriate structural systems. Balali et al. (2014c) compared the usability of AHP and PROMETHEE methods in solving structural system selection problem.

The objective of this study is to propose an integrated MADM approach for selecting the appropriate structural systems. For this purpose, first, an extensive literature review was carried out in order to determine the factors that may affect the selection of a structural system from the managerial perspective. After that, an integrated approach was proposed in order to assist the owner and design team in selecting the structural system from the managerial viewpoint.

In the proposed approach, AHP is used to find the weights of the criteria and VIKOR is used to rank the alternatives. In order to illustrate how the proposed integrated approach can be applied in a real life project, a case study was carried out. The findings of this study revealed that the proposed integrated model can be used a useful tool in selection of the most appropriate structural system to make sound and reasonable decisions.

The abstract, introduction and conclusions sections have been revised in this version of the paper. The abstract section has been changed for enabling better understanding of the objective and findings of the research. The literature review in the introduction section has been considerably improved by adding new references so that the importance and contribution of this paper to the existing body of knowledge can be better understood. In the conclusions section, future direction of this research has been clearly stated.

\section{The Proposed Approach}

The proposed approach includes eight steps, which can be classified under two main stages. The steps of the proposed approach are presented in Fig. 1.

In the first stage, the structural system selection problem is identified. Then, the decision making group, who is in charge of structural system selection in the construction company, is formed, and this group determines the main and sub-criteria that may affect the structural system selection and develops the hierarchy of the structural system selection model. Thirdly, the decision making group constructs pairwise comparison matrices of the structural system selection problem. In the final step of the first stage, the weights of the main and sub-criteria of the structural system selection problem are calculated by using the AHP method.

In the second stage, first, the evaluation matrix, which consists of the assessments of the decision-making group members on the alternative structural systems, is formed. In the second step, the preference scores of the structural system alternatives are calculated by using the VIKOR method. Then, the structural system alternatives are ranked based on their preference scores in a descending order. Finally, the ranking of the alternatives is checked whether it meets the conditions of the VIKOR method.

\subsection{Analytical Hierarchy Process (AHP)}

The AHP is a mathematical theory developed by Thomas L. Saaty in 1980 to solve complex decision-making problems. AHP allows decision makers to model complex problems in a hierarchical structure that demonstrates the relationships among the problem's goal, main criteria, sub-criteria, and alternatives (Saaty, 1980). Since AHP is easy to understand by decision makers, it has been widely 


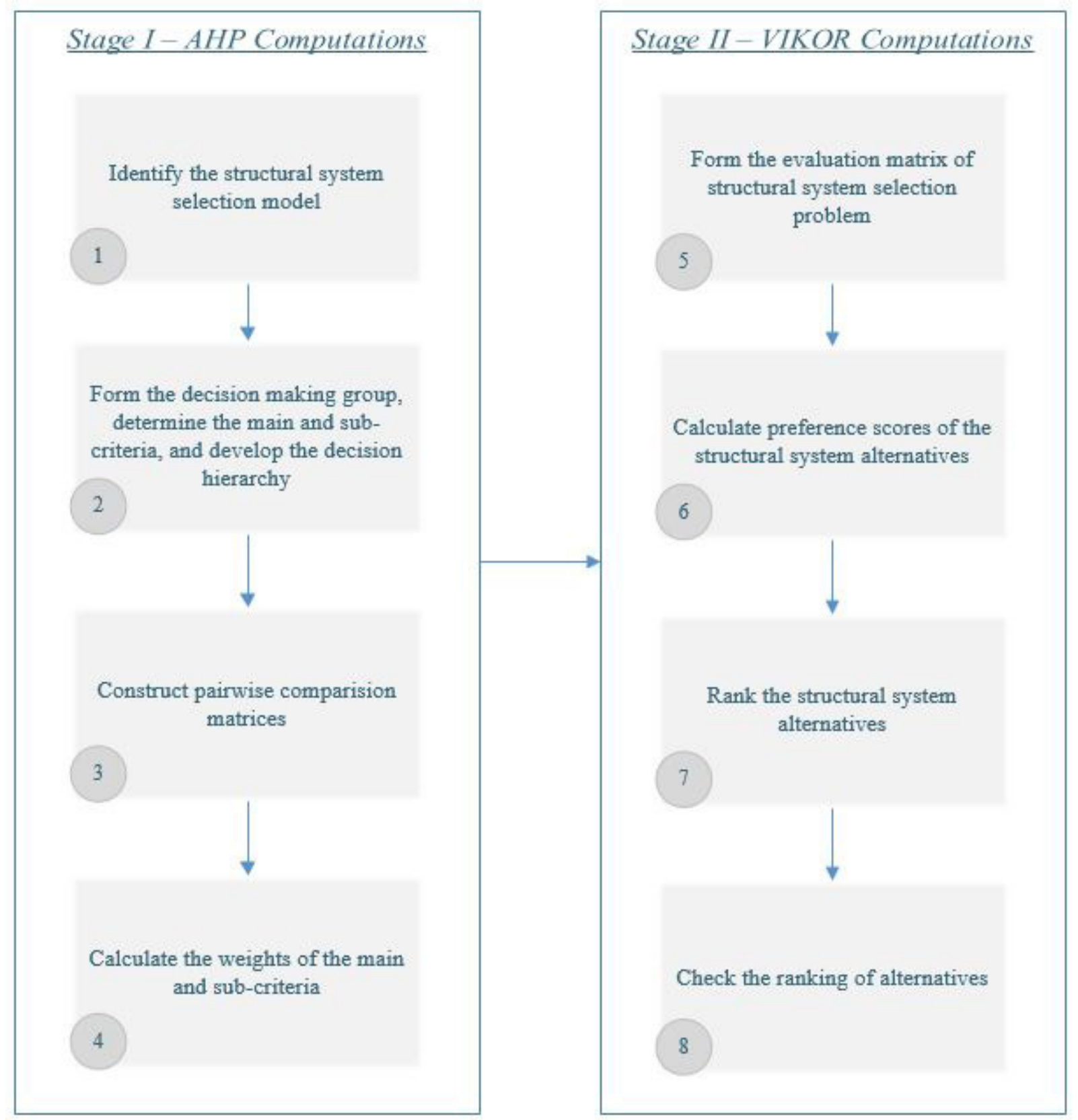

Fig. 1 The steps of the proposed approach

used in the literature and has been performed in almost all applications for multi-attribute-decision making in the last 35 years (Dağdeviren et al., 2009). AHP enables both objective and subjective opinions to be included in the decision-making process (Rajaeian et al., 2017). The calculation steps of AHP are explained below (Zeshui and Cuiping, 1999; Saaty, 2008):

- Step 1: Defining the hierarchical structure of the decision problem (i.e., goal, main criteria, sub-criteria, alternatives).
- Step 2: Constructing pairwise comparison matrices that allows numerical representations of relations between two elements in the hierarchy by using Saaty's Rating Scale (see Table 1).

- Step 3: Calculating the consistency ratio in order to check whether the generated matrices are consistent.

- Step 4: Finding the weights of the alternatives according to the main and/or sub-criteria. 
Table 1 Saaty's Rating Scale (Saaty, 1980)

\begin{tabular}{|c|c|c|}
\hline Imp. & Definition & Explanation \\
\hline 1 & $\begin{array}{l}\text { Equal } \\
\text { importance }\end{array}$ & $\begin{array}{l}\text { Two factors contribute equally to the } \\
\text { objective. }\end{array}$ \\
\hline 3 & $\begin{array}{l}\text { Somewhat more } \\
\text { important }\end{array}$ & $\begin{array}{l}\text { Experience and judgment slightly } \\
\text { favor one over the other. }\end{array}$ \\
\hline 5 & $\begin{array}{l}\text { Much more } \\
\text { important }\end{array}$ & $\begin{array}{l}\text { Experience and judgment strongly } \\
\text { favor one over the other. }\end{array}$ \\
\hline 7 & $\begin{array}{l}\text { Very much } \\
\text { important }\end{array}$ & $\begin{array}{l}\text { Experience and judgment very } \\
\text { strongly favor one over the other. }\end{array}$ \\
\hline 9 & $\begin{array}{l}\text { Absolutely } \\
\text { more important }\end{array}$ & $\begin{array}{c}\text { The evidence favoring one over the } \\
\text { other is one of the highest possible } \\
\text { validity. }\end{array}$ \\
\hline $2,4,6,8$ & $\begin{array}{l}\text { Intermediate } \\
\text { values }\end{array}$ & When compromise is needed. \\
\hline
\end{tabular}

\subsection{Vise Kriterijumska Optimizacija I Kompromisno} Resenje (VIKOR)

VIKOR method was developed by Opricovic and Tzeng in 2004 as a multi-attribute-decision making method to solve certain decision problems that are not measured by the same unit and have contradictory criteria (Opricovic and Tzeng, 2004). The method is an effective tool in multi-attribute-decision making, particularly in a situation where the decision maker is not able, or does not know to express its preference at the beginning of system design. This method provides compromise solutions for problems with contradictory criteria by focusing on ranking and selecting on a set of specific alternatives. In this way, the method helps the decision makers to reach the final decision (Büyüközkan and Görener, 2015). Compromise solution is obtained under the assumption that each alternative is evaluated for each criterion by comparing the values of proximity to the ideal solution. VIKOR method considers maximum group utility and minimum individual regret. The calculation steps of the method are quite simple and clear, which are briefly explained below (Opricovic and Tzeng, 2004):

- Step 1: Constructing the evaluation matrix $X$ with $n$ number of alternatives $(n=1, \ldots . ., i)$ and $\mathrm{m}$ number of criteria $(m=1, \ldots ., j)$.

- Step 2: Identifying the positive ideal solutions of $n$ alternatives according to each criterion $j\left(f_{j}^{*}\right)$ and the negative ideal solutions of $n$ alternatives according to each criterion $j\left(f_{j}^{-}\right)$.

- Step 3: Normalizing the elements of the evaluation matrix.

- Step 4: Computing $S_{i}$ (the maximum group utility, which is the distance between alternative $i$ and the positive ideal solution $f_{j}^{*}$ ) and $R_{i}$ (the minimum individual regret of the opponent, which is the distance between alternative $i$ and the negative ideal solution $f_{j}^{-}$).

- Step 5: Computing $Q_{i}$ (the VIKOR index for each alternative $i$, which is computed using the weight of the strategy of the maximum group utility $q$ ).

- Step 6: Ranking the alternatives, sorting by the values of $Q_{i}$, in decreasing order.

- Step 7: Proposing as a compromise solution the alternative $\left(A_{1}\right)$, which is ranked the best by the measure $Q_{i}$ (minimum), if the following two conditions are satisfied:

○ Condition 1. "Acceptable advantage"

$$
Q\left(A_{2}\right)-Q\left(A_{1}\right) \geq \frac{1}{n-1}
$$

where $A_{2}$ is the alternative with the second position in the ranking list by $Q_{i} ; n$ is the number of alternatives.

- Condition 2. "Acceptable stability in decision making"

Alternative $A_{1}$ must also be the best ranked by $S_{i}$ or/and $R_{i}$. This compromise solution is stable within a decision making process, which could be: "voting by majority rule" (when $q>0.5$ is needed), or by consensus" ( $q \approx 0.5)$, or "with veto" $(q<0.5)$.

If one of the conditions is not satisfied, then a set of compromise solutions is proposed, which consists of:

- Alternatives $A_{1}$ and $A_{2}$ if only Condition 2 is not satisfied, or

- Alternatives $A_{1}, A_{2}, \ldots, A_{K}$ if Condition 1 is not satisfied; and $A_{K}$ is determined by using Equation 2 for maximum $K$.

$$
Q\left(A_{K}\right)-Q\left(A_{1}\right) \approx \frac{1}{n-1} .
$$

The best alternative is the one with the minimum value of $Q_{i}$. The main ranking result is the compromise ranking list of alternatives, and the compromise solution with the "advantage rate".

\section{Application of the Proposed Approach: Case Study} The proposed integrated structural system selection model was applied in a real case, which is a housing project in Istanbul, Turkey. This project consists of 3 basement floors, a ground floor, and 3 normal floors, and total construction area is $822,000 \mathrm{~m}^{2}$. The structural system was selected based on the knowledge and experience of the design team, thus all of four civil engineers, who were 
responsible for the structural system selection, participated in developing this model. The model was developed based on their opinions and evaluations.

\subsection{Decision Hierarchy of the Structural System Selection Problem}

Having conducted face-to-face interviews with the design team members and carried out an extensive review of literature, 5 main criteria have been identified, which include: durability and safety (DS), energy consumption (EC), project characteristics (PC), total cost (TC), and constructability problems (CP). 5 sub-criteria under the main criterion DS are: resistance to external conditions ( $\left.\mathrm{DS}_{1}\right)$, resistance to seismic loads $\left(\mathrm{DS}_{2}\right)$, safety against fire $\left(\mathrm{DS}_{3}\right)$, resistance to wind loads $\left(\mathrm{DS}_{4}\right)$, and lifecycle of the structure $\left(\mathrm{DS}_{5}\right)$. 3 sub-criteria under the main criterion EC include: energy used to construct the structural system $\left(\mathrm{EC}_{1}\right)$, production energy of construction materials $\left(\mathrm{EC}_{2}\right)$, and reusability of construction materials $\left(\mathrm{EC}_{3}\right) .6$ sub-criteria under the main criterion $\mathrm{PC}$ are: the number of floors $\left(\mathrm{PC}_{1}\right)$, need for large spans in the structure $\left(\mathrm{PC}_{2}\right)$, need for huge amount of clear space $\left(\mathrm{PC}_{3}\right)$, aesthetics of the structure $\left(\mathrm{PC}_{4}\right)$, changeability of the internal space $\left(\mathrm{PC}_{5}\right)$, and modularity of the structure $\left(\mathrm{PC}_{6}\right) .2$ sub-criteria under the main criterion TC include: construction cost of the project $\left(\mathrm{TC}_{1}\right)$ and operation and maintenance costs of the project $\left(\mathrm{TC}_{2}\right) .3$ sub-criteria under the main criterion $\mathrm{DC}$ are: construction duration $\left(\mathrm{DC}_{1}\right)$, delivery of construction materials to the site $\left(\mathrm{DC}_{2}\right)$, and availability of laborers and equipment $\left(\mathrm{DC}_{3}\right)$. The design team identified four different structural system alternatives, which are: reinforced concrete $\left(A_{1}\right)$, steel structure $\left(A_{2}\right)$, composite structure $\left(A_{3}\right)$, and precast construction $\left(\mathrm{A}_{4}\right)$. The decision hierarchy of the structural system selection problem is presented in Fig. 2.

\subsection{Determining the Weights of the Main and Sub- criteria of the Selection Problem}

After constructing the decision hierarchy of the structural system selection problem, the AHP method is used to determine the weights of the identified main criteria and sub-criteria. For that reason, four decision makers were asked individually to construct pairwise comparison matrices for the main and sub-criteria of the selection problem. Four pairwise comparison matrices were then aggregated by taking the geometric means of each preference in order to reach a group decision. Finally, the AHP method was employed to find the weights of the main and sub-criteria of the selection problem. Table 2 shows the weights of main criteria of the appropriate structural system selection problem.

According to the findings, the "DS - Durability and Safety" has the highest weight on the selection of a structural system problem. It is followed by the "PC - Project Characteristics" with second higher weight. On the other hand, the "CP - Constructability Problems" has the least

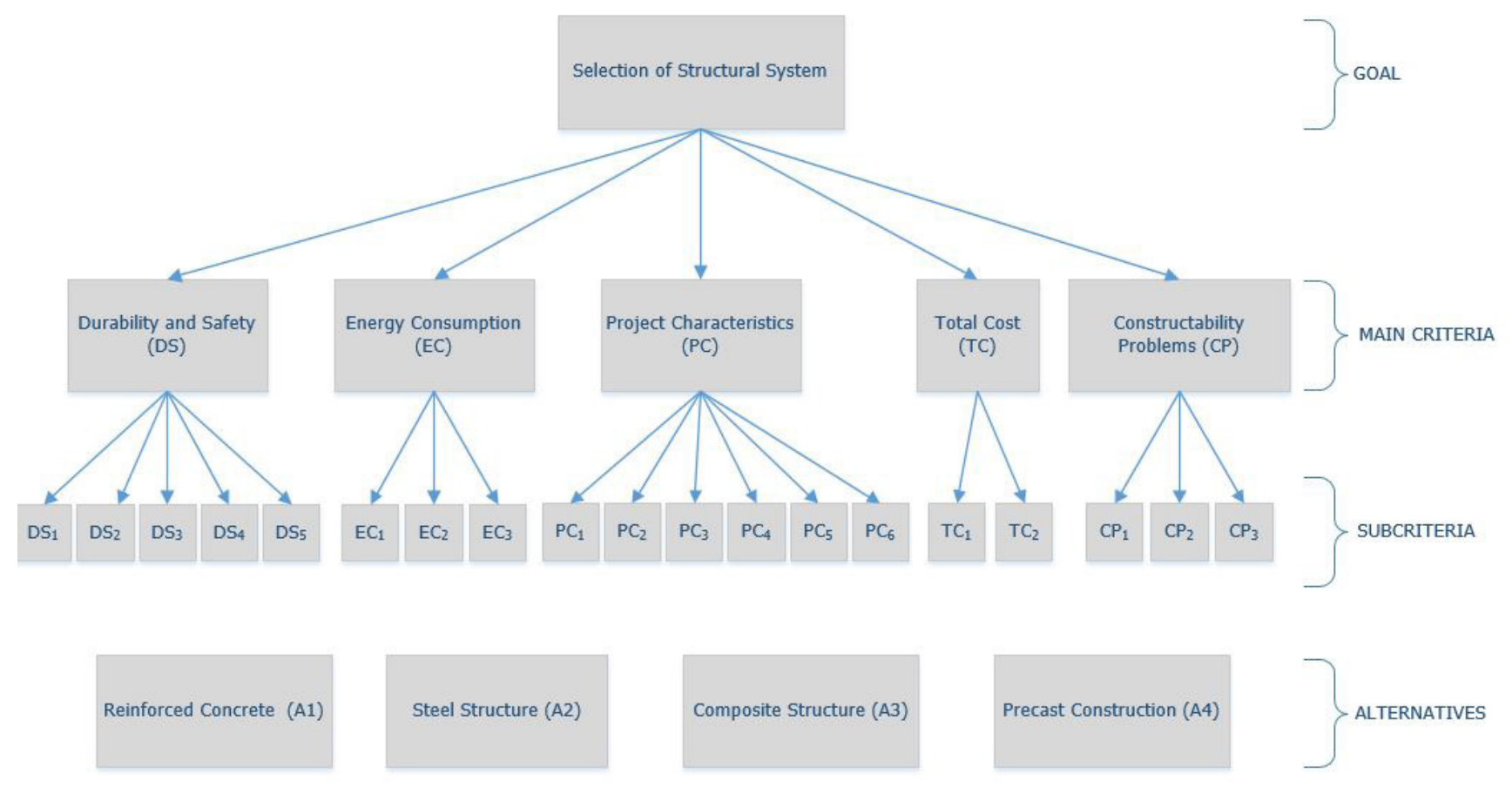

Fig. 2 Decision hierarchy of the structural system selection problem 
Table 2 Aggregated pairwise matrix of main criteria for the structural system selection problem

\begin{tabular}{lcccccc}
\hline Criteria & DS & EC & PC & TC & CP & Weights \\
\hline DS & 1.00 & 2.38 & 1.68 & 2.06 & 2.38 & 0.34 \\
EC & 0.42 & 1.00 & 0.64 & 1.07 & 1.00 & 0.15 \\
PC & 0.59 & 1.57 & 1.00 & 1.57 & 1.57 & 0.22 \\
TC & 0.49 & 0.93 & 0.64 & 1.00 & 1.19 & 0.15 \\
CP & 0.42 & 1.00 & 0.64 & 0.84 & 1.00 & 0.14 \\
& & & & & \multicolumn{3}{c}{ C.R.: 0.0020} \\
\hline
\end{tabular}

importance on the selection process as it has the lowest weight. The consistency ratio (C.R.) of the aggregated pairwise comparison matrix is also checked. Since it is below the 0.10 , it can be concluded that the evaluations are consistent.

The aggregated pairwise comparison matrix of five sub-criteria identified under the "DS - Durability and Safety" criterion is given in Table 3 .

Based on the findings, the " $\mathrm{DS}_{2}$ - Resistance to seismic loads" has the highest weight among all sub-criteria. The aggregated matrix is also consistent (C.R. $=0.0004<0.1)$.

The aggregated pairwise comparison matrix of three sub-criteria of the "EC - Energy Consumption" criterion is given in Table 4.

Based on the findings, the "EC - Energy used to construct the structural system" has the highest weight. The aggregated matrix is also consistent since the consistency ratio is less than 0.1 .

Table 3 Aggregated pairwise matrix of sub-criteria for the "DS - Durability and Safety"

\begin{tabular}{lcccccc}
\hline $\begin{array}{l}\text { Sub- } \\
\text { Criteria }\end{array}$ & $\mathrm{DS}_{1}$ & $\mathrm{DS}_{2}$ & $\mathrm{DS}_{3}$ & $\mathrm{DS}_{4}$ & $\mathrm{DS}_{5}$ & Weights \\
\hline $\mathrm{DS}_{1}$ & 1.00 & 0.45 & 1.41 & 2.21 & 1.68 & 0.20 \\
$\mathrm{DS}_{2}$ & 2.21 & 1.00 & 2.83 & 4.76 & 4.00 & 0.44 \\
$\mathrm{DS}_{3}$ & 0.71 & 0.35 & 1.00 & 1.68 & 1.28 & 0.15 \\
$\mathrm{DS}_{4}$ & 0.45 & 0.21 & 0.59 & 1.00 & 0.76 & 0.09 \\
$\mathrm{DS}_{5}$ & 0.59 & 0.25 & 0.78 & 1.32 & 1.00 & 0.12 \\
& & & & & \multicolumn{2}{c}{ C.R.: 0.0004} \\
\hline
\end{tabular}

Table 4 Aggregated pairwise matrix of sub-criteria for the "EC - Energy Consumption"

\begin{tabular}{lcccc}
\hline Sub-Criteria & $\mathrm{EC}_{1}$ & $\mathrm{EC}_{2}$ & $\mathrm{EC}_{3}$ & Weights \\
\hline $\mathrm{EC}_{1}$ & 1.00 & 1.86 & 1.73 & 0.47 \\
$\mathrm{EC}_{2}$ & 0.54 & 1.00 & 1.00 & 0.26 \\
$\mathrm{EC}_{3}$ & 0.58 & 1.00 & 1.00 & 0.27 \\
& & & & C.R.: 0.0005 \\
\hline
\end{tabular}

The aggregated pairwise comparison matrix of six sub-criteria for the "PC - Project Characteristics" criterion is presented in Table 5 .

Based on the findings, the "PC 1 - The number of floors"has the highest weight. The aggregated matrix is also consistent (C.R. $=0.0003<0.1$ ).

The aggregated pairwise comparison matrix of two sub-criteria identified under the "TC - Total cost" criterion is given in Table 6.

Based on the findings, the " $\mathrm{C}_{1}$ - Construction cost of the project" has the highest weight. The aggregated matrix is also consistent since the consistency ratio is less than 0.1 .

The aggregated pairwise comparison matrix of three sub-criteria of the "CP - Constructability problems" is presented in Table 7.

Based on the findings, the " $\mathrm{CP}_{1}$ - Construction duration" has the highest weight. The aggregated matrix is also consistent (C.R. $=0.0000<0.1)$.

Table 5 Aggregated pairwise matrix of sub-criteria for the "PC - Project Characteristics"

\begin{tabular}{lccccccc}
\hline $\begin{array}{l}\text { Sub- } \\
\text { Criteria }\end{array}$ & $\mathrm{PC}_{1}$ & $\mathrm{PC}_{2}$ & $\mathrm{PC}_{3}$ & $\mathrm{PC}_{4}$ & $\mathrm{PC}_{5}$ & $\mathrm{PC}_{6}$ & Weights \\
\hline $\mathrm{PC}_{1}$ & 1.00 & 1.41 & 2.28 & 2.45 & 2.06 & 2.71 & 0.29 \\
$\mathrm{PC}_{2}$ & 0.71 & 1.00 & 1.86 & 1.86 & 1.57 & 2.21 & 0.22 \\
$\mathrm{PC}_{3}$ & 0.44 & 0.54 & 1.00 & 1.00 & 0.84 & 1.19 & 0.12 \\
$\mathrm{PC}_{4}$ & 0.41 & 0.54 & 1.00 & 1.00 & 0.84 & 1.19 & 0.12 \\
$\mathrm{PC}_{5}$ & 0.49 & 0.64 & 1.19 & 1.19 & 1.00 & 1.41 & 0.14 \\
$\mathrm{PC}_{6}$ & 0.37 & 0.45 & 0.84 & 0.84 & 0.71 & 1.00 & 0.10 \\
& & & & & & C.R.: 0.0003 \\
\hline
\end{tabular}

Table 6 Aggregated pairwise matrix of sub-criteria for the "TC - Total cost"

\begin{tabular}{lccc}
\hline Sub-Criteria & $\mathrm{TC}_{1}$ & $\mathrm{TC}_{2}$ & Weights \\
\hline $\mathrm{TC}_{1}$ & 1.00 & 1.41 & 0.59 \\
$\mathrm{TC}_{2}$ & 0.71 & 1.00 & 0.41 \\
& & & C.R.: 0.0000 \\
\hline
\end{tabular}

Table 7 Aggregated pairwise matrix of sub-criteria for the "CP - Constructability problems"

\begin{tabular}{lcccc}
\hline $\begin{array}{l}\text { Sub- } \\
\text { Criteria }\end{array}$ & $\mathrm{CP}_{1}$ & $\mathrm{CP}_{2}$ & $\mathrm{CP}_{3}$ & Weights \\
\hline $\mathrm{CP}_{1}$ & 1.00 & 2.83 & 3.72 & 0.62 \\
$\mathrm{CP}_{2}$ & 0.35 & 1.00 & 1.32 & 0.22 \\
$\mathrm{CP}_{3}$ & 0.27 & 0.76 & 1.00 & 0.17 \\
& & & & C.R.: 0.0000 \\
\hline
\end{tabular}




\subsection{Finding the Preferences of the Structural System Alternatives with VIKOR Method}

After determining the weights of the main criteria and sub-criteria of the structural system selection problem, VIKOR method was employed to determine the ranking of four structural system alternatives. In the structural system selection problem, the preferences of four decision makers were collected to form the decision matrix.

The data of "construction cost of the project" $\left(\mathrm{TC}_{1}\right)$ is quantitative and measured in Turkish Lira, whereas the other sub-criteria are qualitative and these values were obtained using 1 to 9 point scale (i.e., 1: Very Bad; 9: Very Good).

In order to construct an aggregated decision matrix of the structural system selection problem, geometric means of the individual evaluations of the decision makers on the alternatives were calculated (see Table 8).

In this selection problem, $\mathrm{C}_{1}$ and $\mathrm{C}_{2}$ are cost criteria where the smaller value is always preferred. The rest of them are beneficial criteria where the larger values are desirable. Therefore, $\mathrm{TC}_{1}$ and $\mathrm{TC}_{2}$ are minimized and the rest are maximized.

After forming the aggregated decision matrix, the steps of VIKOR method were followed. First, the best $\mathrm{f}_{\mathrm{j}}^{*}$ and the worst $f_{j}^{-}$values of all criteria were determined (see Table 9).

Then, the normalized decision matrix was computed. After that, the values $S_{i}, R_{i}$, and $Q_{i}$ of four structural system alternatives were calculated. Finally, four structural system alternatives were ranked by $\mathrm{Q}_{\mathrm{i}}$ values in decreasing order. The result matrix is shown in Table 10.

Table 8 Aggregated decision matrix of evaluation criteria for four structural system alternatives

\begin{tabular}{|c|c|c|c|c|c|c|c|}
\hline Criteria & Unit & Reinforced Concrete (A1) & Steel Structure (A2) & Composite Structure (A3) & Precast Construction (A4) & Weight & Opt. Dir. \\
\hline $\mathrm{DS}_{1}$ & S.S & 7.11 & 4.74 & 5.24 & 6.59 & 0.07 & $\uparrow$ \\
\hline $\mathrm{DS}_{2}$ & S.S & 7.97 & 7.20 & 5.66 & 3.98 & 0.15 & $\uparrow$ \\
\hline $\mathrm{DS}_{3}$ & S.S & 6.88 & 2.74 & 2.89 & 5.57 & 0.05 & $\uparrow$ \\
\hline $\mathrm{DS}_{4}$ & S.S & 8.21 & 4.21 & 5.96 & 6.12 & 0.03 & $\uparrow$ \\
\hline $\mathrm{DS}_{5}$ & S.S & 6.40 & 7.20 & 5.23 & 4.86 & 0.04 & $\uparrow$ \\
\hline $\mathrm{EC}_{1}$ & S.S & 7.48 & 6.40 & 6.40 & 5.89 & 0.07 & $\uparrow$ \\
\hline $\mathrm{EC}_{2}$ & S.S & 5.89 & 7.17 & 6.90 & 6.16 & 0.04 & $\uparrow$ \\
\hline $\mathrm{EC}_{3}$ & S.S & 2.99 & 6.88 & 5.69 & 4.46 & 0.04 & $\uparrow$ \\
\hline $\mathrm{PC}_{1}$ & S.S & 6.09 & 6.45 & 4.56 & 6.16 & 0.06 & $\uparrow$ \\
\hline $\mathrm{PC}_{2}$ & S.S & 5.38 & 7.97 & 4.90 & 7.14 & 0.05 & $\uparrow$ \\
\hline $\mathrm{PC}_{3}$ & S.S & 6.74 & 4.74 & 8.00 & 7.97 & 0.03 & $\uparrow$ \\
\hline $\mathrm{PC}_{4}$ & S.S & 6.59 & 7.17 & 6.85 & 5.96 & 0.03 & $\uparrow$ \\
\hline $\mathrm{PC}_{5}$ & S.S & 5.21 & 4.24 & 4.05 & 3.98 & 0.03 & $\uparrow$ \\
\hline $\mathrm{PC}_{6}$ & S.S & 1.86 & 5.58 & 5.18 & 6.59 & 0.02 & $\uparrow$ \\
\hline $\mathrm{TC}_{1}$ & $\mathrm{x} 10^{3} \mathrm{TL}$ & 335 & 795 & 650 & 720 & 0.09 & $\downarrow$ \\
\hline $\mathrm{TC}_{2}$ & S.S & 4.16 & 7.90 & 6.05 & 5.24 & 0.06 & $\downarrow$ \\
\hline $\mathrm{CP}_{1}$ & S.S & 5.00 & 7.09 & 6.62 & 6.51 & 0.09 & $\uparrow$ \\
\hline $\mathrm{CP}_{2}$ & S.S & 6.51 & 5.63 & 5.38 & 4.68 & 0.03 & $\uparrow$ \\
\hline $\mathrm{CP}_{3}$ & S.S & 7.33 & 5.38 & 5.48 & 4.95 & 0.02 & $\uparrow$ \\
\hline
\end{tabular}

Table 9 Aggregated decision matrix of evaluation criteria for the four structural system alternatives

\begin{tabular}{lllllllllllllllllllllll}
\hline & $\mathrm{DS}_{1}$ & $\mathrm{DS}_{2}$ & $\mathrm{DS}_{3}$ & $\mathrm{DS}_{4}$ & $\mathrm{DS}_{5}$ & $\mathrm{EC}_{1}$ & $\mathrm{EC}_{2}$ & $\mathrm{EC}_{3}$ & $\mathrm{PC}_{1}$ & $\mathrm{PC}_{2}$ & $\mathrm{PC}_{3}$ & $\mathrm{PC}_{4}$ & $\mathrm{PC}_{5}$ & $\mathrm{PC}_{6}$ & $\mathrm{C}_{1}$ & $\mathrm{C}_{2}$ & $\mathrm{DC}_{1}$ & $\mathrm{DC}_{2}$ & $\mathrm{DC}_{3}$ \\
\hline $\mathrm{A} 1$ & 7.11 & 7.97 & 6.88 & 8.21 & 6.40 & 7.48 & 5.89 & 2.99 & 6.09 & 5.38 & 6.74 & 6.59 & 5.21 & 1.86 & 335.00 & 4.16 & 5.00 & 6.51 & 7.33 \\
$\mathrm{~A} 2$ & 4.74 & 7.20 & 2.74 & 4.21 & 7.20 & 6.40 & 7.17 & 6.88 & 6.45 & 7.97 & 4.74 & 7.17 & 4.24 & 5.58 & 795.00 & 7.90 & 7.09 & 5.63 & 5.38 & \\
$\mathrm{~A} 3$ & 5.24 & 5.66 & 2.89 & 5.96 & 5.23 & 6.40 & 6.90 & 5.69 & 4.56 & 4.90 & 8.00 & 6.85 & 4.05 & 5.18 & 650.00 & 6.05 & 6.62 & 5.38 & 5.48 \\
$\mathrm{~A} 4$ & 6.59 & 3.98 & 5.57 & 6.12 & 4.86 & 5.89 & 6.16 & 4.36 & 6.16 & 7.14 & 7.97 & 5.96 & 3.98 & 6.59 & 720.00 & 5.24 & 6.51 & 4.68 & 4.95 \\
$\mathrm{f}_{\mathrm{i}}^{*}$ & 7.11 & 7.97 & 6.88 & 8.21 & 7.20 & 7.48 & 7.17 & 6.88 & 6.45 & 7.97 & 8.00 & 7.17 & 5.21 & 6.59 & 335.00 & 4.16 & 7.09 & 6.51 & 7.33 \\
$\mathrm{f}_{\mathrm{i}}^{-}$ & 4.74 & 3.98 & 2.74 & 4.21 & 4.86 & 5.89 & 5.89 & 2.99 & 4.56 & 4.90 & 4.74 & 5.96 & 3.98 & 1.86 & 795.00 & 7.90 & 5.00 & 4.68 & 4.95 \\
\hline
\end{tabular}


Table 10 Result matrix of VIKOR method

\begin{tabular}{lcccccc}
\hline Alternatives & $\mathrm{S}_{\mathrm{i}}$ & $\mathrm{R}_{\mathrm{i}}$ & $\mathrm{Q}_{\mathrm{i}}$ & Ranking & Checking Conditions & \\
\hline A1 & 0.276 & 0.086 & 0.000 & 1.00 & C1. $0.309<0.333$ & $\times$ \\
A2 & 0.469 & 0.089 & 0.309 & 2.00 & C2. A1 $\left(\mathrm{R}_{\mathrm{i}}\right)=\min \left(\mathrm{R}_{\mathrm{i}}\right)$ & $\checkmark$ \\
A3 & 0.614 & 0.087 & 0.507 & 3.00 & & \\
A4 & 0.614 & 0.150 & 1.000 & 4.00 & & \\
\hline
\end{tabular}

Based on the ranking results, although A1 (reinforced concrete construction) is the best alternative with minimum $\mathrm{Q}_{\mathrm{i}}$ value, A1 and A2 (steel structure) are compromise solutions because A1 does not satisfy the "acceptable advantage" condition. According to the ranking results, A3 (composite structure) and A4 (precast construction) ranked third and fourth, respectively. The outcomes of proposed model were discussed with the decision makers and the construction company preferred A1 as the structural system in real life. They stated that they had mostly selected the structural system based on one single criterion, namely cost, and had not considered other factors. They concluded that they could employ the proposed model in future to make sound decisions.

\section{Conclusions}

Selection of an appropriate structural system is a difficult task in design phase as there are many factors that need to be taken into consideration. An extensive literature review was carried out in order to identify the factors that may affect the selection of a structural system from the managerial perspective.

\section{References}

Balali, V., Mottaghi, A., Shoghli, O., Golabchi, M. (2014a) "Selection of appropriate material, construction technique, and structural system of bridges by use of multicriteria decision-making method", Transportation Research Record: Journal of the Transportation Research Board, 2431, pp. 79-87.

https://doi.org/10.3141/2431-11

Balali, V., Zahraie, B., Hosseini, A., Roozbahani, A. (2010) "Selecting appropriate structural system: Application of PROMETHEE decision making method", In: 2nd International Conference on Engineering Systems Management and Its Applications -ICESMA, Sharjah, United Arab Emirates, pp. 1-6.

Balali, V., Zahraie, B., Roozbahani, A. (2014b) "A comparison of AHP and PROMETHEE family decision making methods for selection of building structural system", American Journal of Civil Engineering and Architecture, 2(5), pp. 149-159.

https://doi.org/10.12691/ajcea-2-5-1
This study proposed an integrated model for selecting the most appropriate structural system. Two multi-attribute-decision-making methods, namely AHP and VIKOR, were integrated to find the most appropriate structural system option among the alternatives. In the integrated model, the AHP method was used to determine the weights of the identified main criteria and their constituent sub-criteria. The VIKOR method was used to determine the ranking of the structural system alternatives.

In order to demonstrate how the proposed integrated approach can be performed in a real life project, a case study was carried out. The findings of the proposed integrated model were discussed with the decision makers, who participated in this study. They stated that the proposed approach could be easily employed as a guideline in selecting the most appropriate structural system from the managerial viewpoint.

In future studies, the number of criteria can be increased, different MADM methods can be employed to solve the same structural system selection problem, and then the findings of this study can be compared.

Balali, V., Zahraie, B., Roozbahani, A. (2014c) "Integration of ELECTRE III and PROMETHEE II decision-making methods with an interval approach: Application in selection of appropriate structural systems", Journal of Computing in Civil Engineering, 28(2), pp. 297-314.

https://doi.org/10.1061/(ASCE)CP.1943-5487.0000254

Büyüközkan, G., Görener, A. (2015) "Evaluation of product development partners using an integrated AHP-VIKOR Model", Kybernetes, 44(2), pp. 220-237. https://doi.org/10.1108/K-01-2014-0019

Chen, W. F., Lui, E. M. (2005) "Principles of Structural Design", 2nd ed., CRC Press, Boca Raton, FL, USA.

Dağdeviren, M., Yavuz, S., Kılınç, N. (2009) "Weapon selection using the AHP and TOPSIS methods under fuzzy environment", Expert Systems with Applications, 36, pp. 8143-8151. https://doi.org/10.1016/j.eswa.2008.10.016 
Golabchi, M. (2008) "A knowledge-based expert system for selection of appropriate structural systems for large spans", Asian Journal of Civil Engineering (Building and Housing), 9(2), pp. 179-191.

Messner, J., Sanvido, V., Kumara, R. (1994) "StructNet: A neural network for structural system selection", Computer-Aided Civil and Infrastructure Engineering. 9(2), pp. 109-118. https://doi.org/10.1111/j.1467-8667.1994.tb00366.x

Rivard, R. H., Leclercq, R. P. (2006) "From architectural sketches to feasible structural systems", In: Design Computing and Cognition '06, Springer, Dordrecht, The Netherlands, pp. 675-694. https://doi.org/10.1007/978-1-4020-5131-9_35

Opricovic, S., Tzeng, G. H. (2004) "Compromise solution by MCDM methods: A comparative analysis of VIKOR and TOPSIS", European Journal of Operational Research, 156(2), pp. 445-455. https://doi.org/10.1016/S0377-2217(03)00020-1

Polat, G., Turkoglu, H., Damci, A. (2018) "An integrated multi-attribute- decision making approach for selecting structural system: A case study", In: Creative Construction Conference - CCC2018, Ljubljana, Slovenia.

Rajaeian, M. M., Cater-Steel, A., Lane, M., A. (2017) "A systematic literature review and critical assessment of model-driven decision support for IT outsourcing", Decision Support Systems, 102, pp. 42-56. https://doi.org/10.1016/j.dss.2017.07.002

Rogers, M. (2000) "Using Electre III to aid the choice of housing construction process within structural engineering", Construction Management and Economics, 18(3), pp. 333-342.

https://doi.org/10.1080/014461900370690
Saaty, T. L. (1980) "The Analytic Hierarchy Process", McGraw-Hill, New York, USA.

Saaty, T. L. (2008) "Decision making with the Analytic Hierarchy Process", International Journal of Services Sciences, 1(1), pp. 83-98. https://doi.org/10.1504/IJSSCI.2008.017590

Shamrani, O. S., Schierle, G. G. (2007) "Selection of optimum structural systems and materials", Computer Aided Optimum Design in Engineering X, WIT Press, Southampton, UK, pp. 129-140.

Tabarak, M. A. B., Sher, W. D. (2003) "Artificial neural network for the selection of buildable structural systems", Engineering, Construction and Architectural Management, 10(4), pp. 263-271. https://doi.org/10.1108/09699980310489979

Wong, J., Li, H., Lai, J. (2008) "Evaluating the system intelligence of the intelligent building systems I: Development of key intelligent indicators and conceptual analytical framework", Automation in Construction, 17(3), pp. 284-302. https://doi.org/10.1016/j.autcon.2007.06.002

Zeshui, X., Cuiping, W., A. (1999) "A consistency improving method in the Analytic Hierarchy Process", European Journal of Operational Research, 116(2), pp. 443-449. https://doi.org/10.1016/S0377-2217(98)00109-X 